\title{
Crack propagation characteristics and mechanism of energy evolution in intermittent externally fissured sandstone
}

Hui Yu

Shandong University of Technology

Shaowei Liu ( $D$ lswxll@126.com )

Housheng Jia

Henan Polytechnic University

Huaichang Zheng

Shandong University of Technology

Zhihe Liu

Shandong University of Technology

\section{Research}

Keywords: Externally fissured sandstone, Rock bridge angle, Confining pressure, Energy, Particle flow code

Posted Date: May 20th, 2020

DOI: https://doi.org/10.21203/rs.3.rs-29394/v1

License: (c) (1) This work is licensed under a Creative Commons Attribution 4.0 International License.

Read Full License 


\title{
Crack propagation characteristics and mechanism of energy evolution in intermittent externally fissured sandstone
}

\author{
Hui Yu ${ }^{1,2,3}$, Shaowei Liu $^{3 *}$, Housheng $\mathrm{Jia}^{3}$, Huaichang Zheng ${ }^{1}$, Zhihe Liu ${ }^{1}$ \\ ${ }^{1}$ School of Resources and Environmental Engineering, Shandong University of Technology, Zibo 255000, China \\ ${ }^{2}$ State and Local Joint Engineering Laboratory for Gas Drainage \& Ground Control of Deep Mines, Henan Polytechnic University, Jiaozuo 454000, China; \\ ${ }^{3}$ School of Energy Science and Engineering, Henan Polytechnic University, Jiaozuo 454000, China
}

\begin{abstract}
Geostress environment and fracture distribution both exert important influences on the mechanical properties and failure modes of fissured rock masses. Laboratory test results are presented here to simulate particle flow code (PFC) in externally double-fissured sandstone samples. Mechanical responses of confining pressure and rock bridge angle on stress-strain curves as well as mesoscale damage and fracture propagation in these samples were studied in order to elucidate energy dissipation mechanisms. The results of this analysis show that fissured sandstone peak strength and elastic modulus as well as peak axial and lateral strain increase significantly as rock bridge angle decreases while peak strength increases slightly in concert with confining pressure. Rock bridge angle exerts an important influence on macro fracturing patterns; when $\beta=0^{\circ}$, wing cracks from two pre-existing external fissures propagate in opposite directions, but when $\beta=60^{\circ}$, the inner tips of two external fissures become directly connected. The evolution of specimen fracturing passes through four main stages, elastic compression deformation, stable crack development, unstable crack development, and post-peak accelerated crack development. Internal contact forces reach maximum values at the peak stress point, while cracks are mainly tensile and shear examples are mostly distributed at orientations between $80^{\circ}$ and $100^{\circ}$. Shear cracks are mainly generated along the direction of main stress, $\sigma_{1}$, while pre-peak dissipated energy is small, and increases rapidly at the post-peak. As rock bridge angle decreases, peak strain and boundary energies both increase significantly. Data show that energy and rock bridge angle are approximately linearly positively correlated.
\end{abstract}

Keywords Externally fissured sandstone - Rock bridge angle - Confining pressure - Energy - Particle flow code

\section{Introduction}

Natural rocks usually contain abundant joint fissures which exert an important influence on mechanical behavior (Fig. 1). A substantial body of engineering research has shown that rock instability is often caused by the expansion and penetration of internal fractures. These often result in a new shear sliding surface and eventually a macro-fracture, which leads to rock mass instability of rock mass (Tang et al. 2020; Yang et al. 2020). In underground engineering, for example, accidents like roof caving and pillar instability are common because of fracture expansion. Research on the mechanical properties of fissured rock masses has therefore always been an important component of rock mechanics internationally. In a geological engineering context, fracture distributions and the in-situ stress environment of rock masses exert substantial influences on mechanical behavior. Surrounding rock can be more prone to failure and instability in a roadway experiencing high stress or affected by mining, for example. Studying the evolution of fissured rock damage under different confining pressures is therefore of considerable significance to reveal the mechanisms of fracture propagation and transfixion.

Researchers around the world have performed numerous effective studies on the damage mechanics and behavior of fissured rocks. Particle flow code (PFC) has been used, for example, to study the mechanical properties of rock specimens with single fractures in order to understand their influence on tensile strength and crack growth (Yang et al. 2014; Huang et al. 2013; Tian et al. 2017). Pan et al. (Pan et al. 2019; Zhou et al. 2013; Wang et al.

*Corresponding author: Shaowei LiuＥ-mail: 1swxll@126.com 
2018) studied the macro-mechanical behavior of sandstones containing more than two fractures and analyzed sample crack propagation and failure modes under uniaxial and triaxial compression. In order to quantitatively describe the damage evolution of fissured rock masses, these workers constructed a nonlinear behavior and damage model (Kucewicz et al. 2020; Li et al. 2019; Silva et al. 2020; Baranowski et al. 2020). The deformability and strength of three-dimensional (3D) fractured rock masses were measured in this study using numerical methods (Mahnaz et al. 2018; Ju et al. 2018). Similarly, Mu et al. (Mu et al. 2015; Liu et al. 2019; Mardalizad et al. 2019; Qiu et al. 2019) performed numerical acoustic emission and energy dissipation simulations for sandstones in order to elucidate the law of acoustic emission with dissipated energy. Park et al. (Park et al. 2010; Lee et al. 2011; Ha et al. 2015; Cheng et al. 2019) described the damage and failure characteristics of materially similar rocks with pre-existing cracks and compared the factors controlling crack growth in specimens that had open and closed flaws. Ghadirian et al. (Ghadirian et al. 2019; Sangsefidi et al. 2020) also carried out a fracture analysis of rock specimens weakened by U-shaped notches. This previous research has mainly focused on the mechanical behavior of specimens with existing internal fissures; limited work to date has been carried out on damage and energy dissipation of sandstones with external fissures under different confining pressures and rock bridge angles.

A series of PFC numerical simulations are used in this study to assess the stress, strain, strength, and other macro-mechanical characteristics of externally double-fissured sandstone under different confining pressures and rock bridge angles. This research aims to reveal micro-mechanical response characteristics and energy dissipation mechanism.

\section{Numerical model and micro-parameter calibration}

\subsection{Model construction}

A PFC numerical model with a height $\times$ diameter of $140 \mathrm{~mm} \times 70 \mathrm{~mm}$ was established based on the roof sandstone in Shihu Mine, Shanxi Province, China. The parallel bond model was used for contacts between particles; a total of 42,081 particles were generated in this model, including 87,793 contacts. The minimum particle radius was 0.26 $\mathrm{mm}$ and the ratio of particle radius was 1.5 .

The model loading process was controlled by displacement in this analysis. This means that upper and lower walls as plates were loaded at a constant rate of $0.02 \mathrm{~mm} / \mathrm{s}$ until a specimen was damaged. As part of the loading process, the model automatically records stress-strain, micro-crack number, and crack growth state. The evolution of strain, dissipated, and other energies in the model were recorded in real time using a built-in energy variable.

The distribution of pre-existing fissures is shown in Fig. 2. Rock bridge length in this analysis was denoted as $l=40 \mathrm{~mm}$, the width of pre-existing fissures (1) and (2) was $1.4 \mathrm{~mm}$, and the inclination angle of fissures was $\alpha=45^{\circ}$. This means that A and B mark the ends of fissure (1), while C and D mark the ends of fissure (2). The effects of different rock bridge angle, $\beta$, and confining pressure, $\sigma_{3}$, on rock mechanical properties and energy dissipation mechanism were then studied.

\subsection{Micro-parameter calibration}

The macro-mechanical behavior of a specimen in this model is determined by micro-parameters such as parallel bond modulus, the linear contact modulus of particles, stiffness ratio, and tangential and normal bonding strength. It is clear that different micro-mechanical parameters will lead to different macroscopic mechanical characteristics such as elastic modulus and peak strength. Thus, in order to remain consistent regarding macro-behaviors such as the stress-strain curves obtained from laboratory tests, it is necessary to calibrate PFC meso-parameters so that simulation results reflect real rock mechanical behaviors. Rock specimens were therefore processed in the laboratory test inside a cylinder with a diameter of $50 \mathrm{~mm}$ and a height of $100 \mathrm{~mm}$ so that non-parallelism of the two ends was less than $0.05 \mathrm{~mm}$. Rock specimens were tested using an RMT-150 rock tester under triaxial 
compression $\left(\sigma_{3}=5 \mathrm{MPa}\right)$ and with a loading rate consistent with PFC simulations based on macro-mechanical parameters. Micro-parameters were calibrated as follows:

1) Adjusting the contact and parallel bond moduli enabled the elastic modulus to be obtained, similar to experimental results;

2) Fixing the linear contact and parallel bond moduli meant that the appropriate Poisson's ratio value was obtained by adjusting stiffness ratio;

3) Adjusting normal and the tangential bond strengths enabled the reasonable compression tensile strength ratio to be obtained;

4) Keeping the ratio between normal and tangential bond strengths unchanged, reasonable tensile and compressive strengths were obtained by multiplying a coefficient;

5) On the basis of laboratory test macro-mechanical parameters, micro-mechanical parameters finely adjusted (Table 1).

Laboratory test results and numerical simulations (Fig. 3 and Fig. 4) reveal that the PFC approach better reflects the mechanical properties of sandstone. Thus, on the basis of calibrated micro-mechanical parameters, a PFC simulation was performed for externally fissured sandstone under different confining pressures.

\section{Macro-mechanical behavior}

\subsection{Stress-strain curve analysis}

Graphs in Fig. 5 are stress-strain curves for sandstone specimens with external double-fissures. These curves show that:

(1) As rock bridge angle increases, the peak strength and elastic modulus of externally double fissured specimens obviously decrease. At the same time, axial and lateral peak strain values also significantly decrease, with the latter smaller than the former.

(2) At the same rock bridge angle, the peak value of deviatoric stress, $\sigma_{1}-\sigma_{3}$, and axial strain both decrease as confining pressure increases, although peak stress, $\sigma_{1}$, increases in concert with this pressure. Confining pressure has little effect on pre-peak elastic modulus.

(3) There is a short period of stress increase in the post-peak stage, after which stress decreases to a certain extent. This indicates that specimens have some residual strength with crack growth and that rearrangement is possible in the post-peak stage.

\subsection{Peak strength analysis}

The data in Fig. 6 show the relationships between peak strength, $\sigma_{1}$, rock bridge angle, and confining pressure. Data in Table 2 are peak strength, axial, lateral, and volume strain values as well as the elastic modulus for externally fissured sandstones under different rock bridge angle when $\sigma_{3}=10 \mathrm{MPa}$. These results imply that:

(1) Given the same rock bridge angle, as confining pressure increases, the peak strength of externally fissured sandstone also increases significantly. Indeed, when the confining pressure increases from $5 \mathrm{MPa}$ to $25 \mathrm{MPa}$ at $\beta=$ $30^{\circ}$, peak strength increases from 55.3 $\mathrm{MPa}$ to $64.5 \mathrm{MPa}$. This result shows that confining pressure can significantly improve the compressive strength of fissured sandstone.

(2) Given the same confining pressure, rock bridge angle exerts a marked influence on both peak strength and peak axial strain values. Thus, when $\sigma_{3}=10 \mathrm{MPa}$, as rock bridge angle increases, peak strength and peak axial strain as well as lateral and volume strain and elastic modulus all gradually decrease.

\subsection{Macro-fracturing patterns}

The data presented in Fig. 7 shows final fracturing patterns for specimens with different rock bridge angles under 
variable confining pressures (i.e., $5 \mathrm{MPa}, 15 \mathrm{MPa}$, and $25 \mathrm{MPa}$ ).

Results show that at low confining pressure ( $\sigma_{3}=5 \mathrm{MPa}$ ) when $\beta=0^{\circ}$, external double -fissures (1) and (2) initiated wing cracks 1 and 2 in opposite directions, respectively, and gradually extended to form a macro-failure surface before penetrating the specimen. In contrast, when $\beta=30^{\circ}$, the propagation direction of wing cracks 3 and 4 was the same as in the $\beta=0^{\circ}$ case, but obvious macroscopic crack 5 formed between the inner tips of external fissures. This meant that fissures (1) and (2) did not directly connect with one another. As rock bridge angle increased further $\left(\beta=45^{\circ}\right)$, the two wings cracks 6 and 7 expanded upward and finally converged. In later experiments, when $\beta=60^{\circ}$ and $\beta=90^{\circ}$, the inner tip of the two external fissures directly connected with one another, and macroscopic cracks 8 and 9 were generated along the lines of fissure tips A and C. These cracks finally fractured the specimen.

At high confining pressures, specimen macro- fracturing patterns given different rock bridge angles were similar to those seen at low confining pressures. As a high confining pressure can significantly improve specimen peak strength, cracks formed significantly more often than in samples at low confining pressure $\left(\sigma_{3}=5 \mathrm{MPa}\right)$. Indeed, data show that when $\sigma_{3}=15 \mathrm{MPa}$ and $\beta=30^{\circ}$, fissure (2) still generated wing crack 10 in a downward direct, but macroscopic crack 11 eventually penetrated the specimen. In cases where $\sigma_{3}=25 \mathrm{MPa}$ and $\beta=0^{\circ}$, pre-existing fissures (1) and (2) were filled, resulting in a more developed macro-fracturing zone due to serious post-peak breaking. However, when $\beta=30^{\circ}$, wing crack 12 produced by fissure (2) no longer propagated downward under low confining pressure, but propagated upward and merged with wing crack 13 that had been produced by fissure (1).

\section{The evolution of mesoscale damage}

Macro-fractures in specimens are mainly caused by the development and transfixion of cracks during compression. This means that PFC can be used to monitor fracture development processes as well as the distribution of particle contact force in real time to reveal damage processes at the microscopic level.

The parallel bond model was used for energy calculations and to simulate mechanical behavior in particle-to-particle contact. Particle-to-particle contact forces were calculated as follows (Fig. 8):

$$
\begin{aligned}
& \left\{\begin{array}{l}
F_{\mathrm{c}}=F^{1}+F^{\mathrm{d}}+\bar{F} \\
M_{\mathrm{c}}=\bar{M}
\end{array}\right. \\
& \left\{\begin{array}{l}
F^{1}=-F_{\mathrm{n}} \hat{\mathrm{n}}_{\mathrm{c}}+F_{\mathrm{s}}^{1} \\
\bar{F}=-\overline{F_{\mathrm{n}}} \hat{\mathrm{n}}_{\mathrm{c}}+\bar{F}_{\mathrm{s}}
\end{array}\right.
\end{aligned}
$$

In these expression, $F_{\mathrm{c}}$ denotes the linear contact force, $F^{1}$ is the linear contact force, $\bar{F}$ is the parallel-bond force, $F^{\mathrm{d}}$ is the damping force, and $\bar{M}$ is the parallel bond moment.

Thus, taking $\beta=30^{\circ}$ and $\sigma_{3}=10 \mathrm{MPa}$ as one example, the crack growth process and contact force field were traced and analyzed. The relationship between deviator stress and micro-crack number with axial strain are shown in Fig. 9, while the evolution of micro-cracks and the contact force distribution are shown in Fig. 10. These data show that damage evolution in fissured sandstones at the mesoscale can be subdivided into four stages.

(1) Stage I of elastic compression deformation. Prior to point A, a specimen is in an elastic compression state and no obvious crack is forming internally. The contact force is evenly distributed, but concentrated at pre-existing fissure tips. The maximum contact force of the specimen at point $\mathrm{A}$ is $125 \mathrm{kN}$, and rock mechanical properties at this stage are basically reversible. 
(2) Stage II of stable crack growth. Once loaded to point A, the inner tip of the pre-existing fissure reaches crack initiation stress and a wing crack begins to propagate. As loading is continuous, more and more new cracks appear; at this stage, the specimen begins to 'soften' at point A. Increase in inelastic volume strain is mainly due to the acceleration of micro-crack growth caused by deviator stress and internal contact forces continue to increase.

(3) Stage III of unstable crack growth. At point B, the specimen yields and contact force reaches $285 \mathrm{kN}$. Speed of crack growth is accelerated, and the number of these features begins to mutation. Point $\mathrm{C}$ denotes the peak-stress point, and contact force also reaches the maximum value for the whole loading process, $332 \mathrm{kN}$.

(4) Stage IV of post-peak accelerated crack growth. The process subsequent point C is the post-peak stage. At this stage, a large number of internal cracks are produced, forming a macro-crack band and completely penetrating the specimen. As the rock sample is now destroyed, particle contact force gradually decreases. The contact force concentration area then evolves from the inner tip of the fissure to the middle of the specimen, distributed along the direction of principal stress, $\sigma_{1}$. Maximum contact force at failure point $\mathrm{E}$ is $201 \mathrm{kN}$ when specimen finally breaks.

Internal crack and contact force of the specimen change markedly during the loading process, reflecting micro-crack growth and particle contact force evolution. Although a crack comprises both tension and shear component, the former is dominant. This implies that contact failure is mainly tensile.

The data presented in Fig. 11 show micro-crack directional distribution after final specimen failure (point E). Data show that tension cracks are obviously more abundant than their shear counterparts at all angles. Indeed, the distribution of shear crack occurs mostly at directions between $80^{\circ}$ and $100^{\circ}$ which indicates that these mainly occur along the direction of principal stress, $\sigma_{1}$.

\section{The mechanism of energy evolution}

\subsection{Energy calculation}

Throughout the loading process, upper and lower loading plates as well as left and right walls work on the specimen. One component of the energy that causes rock internal damage, plastic deformation, and crack expansion is irreversible dissipated energy, while the other, strain energy, is stored in the rock. This means that, from an energy perspective, specimen damage and fracturing is the result of energy accumulation and the transformation of internal strain and dissipated energies. Thus, assuming that there is no heat exchange outside the system, all work done is converted into dissipated and strain energy (Peng et al. 2014; Deng et al. 2016; Zhao et al. 2013), as follows:

$$
U=U_{\mathrm{e}}+U_{\mathrm{d}}
$$

In this expression, $U$ is boundary energy, $U_{\mathrm{e}}$ is strain energy, and $U_{\mathrm{d}}$ is dissipated energy. In a PFC model, boundary energy is the total work done by the upper and lower loading plates as well as the left and right walls. Dissipated energy is composed of particle slip, damping, and kinetic energies; the strain energy is composed of strain energy, $E_{\mathrm{k}}$, and bond strain energy, $\overline{E_{\mathrm{k}}}$, as follows:

$$
\begin{gathered}
U_{\mathrm{e}}=E_{\mathrm{k}}+\overline{E_{\mathrm{k}}} \\
E_{\mathrm{k}}=\frac{1}{2}\left(\frac{\left(F_{\mathrm{n}}^{1}\right)^{2}}{k_{\mathrm{n}}}+\frac{\left\|F_{\mathrm{s}}^{1}\right\|^{2}}{k_{\mathrm{s}}}\right) \\
\overline{E_{\mathrm{k}}}=\frac{1}{2}\left(\frac{\bar{F}_{\mathrm{n}}^{2}}{\bar{k}_{\mathrm{n}} \bar{A}}+\frac{\left\|\bar{F}_{\mathrm{s}}\right\|^{2}}{\bar{k}_{\mathrm{s}} \bar{A} \overline{\bar{M}_{\mathrm{s}}}}+\frac{\bar{M}_{\mathrm{t}}^{2}}{\bar{k}_{\mathrm{J}}}+\frac{\left\|\bar{M}_{\mathrm{b}}\right\|^{2}}{\bar{k}_{\mathrm{n}} \bar{I}}\right)
\end{gathered}
$$


In these expressions, $F_{\mathrm{n}}^{1}$ and $F_{\mathrm{s}}^{1}$ denote normal and tangential particle contact forces, respectively, while $k_{\mathrm{n}}$ and $k_{\mathrm{s}}$ are normal and tangential particle contact stiffness values, respectively. Normal and tangential parallel-bond forces are therefore $\bar{F}_{\mathrm{n}}$ and $\bar{F}_{\mathrm{s}}$, while normal and tangential parallel bond stiffness are $\bar{k}_{\mathrm{n}}$ and $\bar{k}_{\mathrm{s}}$, respectively. Parameters $\bar{M}_{\mathrm{t}}$ and $\bar{M}_{\mathrm{b}}$ denote the parallel bond torque and bending moment, respectively. The parallel bond cross-sectional area is $\bar{A}, \bar{J}$ denotes the polar moment of inertia of a parallel bonded section, and $\bar{I}$ is the moment of inertia.

This energy principle enabled evolution of the fissured sandstone to be analyzed. Energy dissipation characteristics under different confining pressures and rock bridge angles were revealed.

\subsection{Energy evolution}

Applying the fish command in PFC, internal energy evolution of the model was tracked and analyzed so that internal dissipated and strain energies could be monitored in real time. The data in Fig. 12 are plotted as an energy evolution curve obtained during the loading process when $\beta=30^{\circ}$ and $\sigma_{3}=10 \mathrm{MPa}$. Energy evolution can be divided into three stages:

(1) Stage I, non-dissipated energy. Prior to point A, no obvious cracks were presented in the specimen which means that boundary energy is all transformed into strain energy. The growth rate of strain energy gradually increases because of specimen pore compaction.

(2) Stage II, slow dissipated energy development. At the point when fissure tip stress reaches initiation stress (point A), an internal crack begins to form and expand as surrounding particles slide slowly. Frictional and dissipated energies in the model start to increase; growth rate remains slow, however, while strain and boundary energies still grow rapidly.

(3) Stage III, dissipated energy accelerated development. Loading to peak-stress point C means that internal strain energy reaches its highest value. Subsequent to this post-peak stage, strain energy stored in the specimen is released rapidly and converted into dissipated energy, used for the generation and expansion of cracks. Data show that slip and dissipated energies of particles in the model also increase exponentially.

Through the whole compression process, kinetic energy in the model changes the least. It is the case that in the post-peak stage, growth rate increased and the proportion of kinetic to total energy remained small. Data show that particle motion remained relatively smooth throughout the compression process and that internal dynamic equilibrium was achieved. The evolution of slip and dissipated energies were basically the same; frictional sliding comprised one of the main ways for internal energy to be dissipated.

The data in Fig. 13 also show that the law of energy and crack evolution remains very similar under different confining pressures and rock bridge angles. There is a positive correlation between dissipated energy and the number of cracks; a large number are produced in the post-peak stage and dissipated energy rises sharply, which indicates that an increase in this energy is mainly due to crack propagation and penetration. At the same confining pressure, peak strain, dissipated, and boundary energies all decrease as rock bridge angle increase. Given the same rock bridge angle, a larger confining pressure means larger peak strain, dissipated, and boundary energy values.

\subsection{The influence of confining pressure and rock bridge angle on energy evolution}

The data in Fig. 14 reveal the relationship between peak strain and boundary energies versus confining pressure under different rock bridge angles. These data show that as confining pressure increases, so does the peak strain energy of specimens with different rock bridge angles even though this range of change remains small. At the same confining pressure, the larger the angle of a rock bridge is, the smaller the peak strain energy will also be, which indicates that the angle of bridge plays a key role in externally fissured specimen energy evolution.

The data presented in Fig. 15 show the fitting curve of the relationship between strain and boundary energies with rock bridge angle at the specimen peak stress point when $\sigma_{3}=10 \mathrm{MPa}$. Thus, as rock bridge angle decreases, strain 
and boundary energies increase gradually under the same confining pressure. This indicates that the smaller a rock bridge angle is, the greater the energy required for failure will be, and the greater the stored strain energy. Thus, energy and rock bridge angle are approximately linearly and positively correlated with one another. Goodness of fit is good in this case and the determinable coefficient $R^{2}$ falls very close to 1 . A regression line can be used to reflect the internal relationship between energy characteristics and rock bridge angle.

\section{Conclusions}

This work studies the effects of confining pressure and rock bridge angle on the macro and micro mechanical properties, internal damage and crack growth of fissured rock masses, and clarifies the energy evolution mechanism in the process of rock damage. This provides the theoretical basis for the failure and instability of underground fissured rock engineering. A number of conclusions result from this research:

(1) At the same confining pressure, as rock bridge angle decreases, the peak strength and elastic modulus of an externally fissured sandstone both increase significantly, alongside peak axial and lateral strain values. Indeed, at the same rock bridge angle, data show that confining pressure has little effect on elastic modulus, but an increase in confining pressure can improve specimen peak strength.

(2) Rock bridge angle exerts an important influence on specimen macro-fracturing patterns. Thus, when rock bridge angle is small, wing cracks generated by two external fissures expand in opposite directions and the inner tips of this fissure do not directly connect. As rock bridge angle increases, the direction of wing crack propagation changes markedly, connecting the inner tips of these fissures. A change in confining pressure also leads to changes in crack propagation direction and the number of these features also obviously increases at pressures.

(3) Crack evolution passes through four stages, elastic compression deformation, stable crack growth, unstable crack growth, and post-peak accelerated crack growth. The internal contact force at the peak-stress point reaches a maximum value and cracks are mainly tensile, which indicates that particle contacts are mainly tensile failure. The distribution of shear cracks is mostly in directions between $80^{\circ}$ and $100^{\circ}$, which indicates that these features mainly occur along the direction of principal stress, $\sigma_{1}$.

(4) Throughout the loading process, energy evolution can be divided into three stages, non-dissipated, slow dissipated development, and accelerated dissipated development. As confining pressure increases, energy increase remains small, but peak strain and boundary energy increase significantly with a decrease in rock bridge angle. This means that energy and rock bridge angle are approximately linearly positively correlated. Pre-peak dissipated energy remains small. Thus, from the peak stress point to final specimen failure, dissipated energy increases rapidly.

\section{Data Availability}

The data used to support the findings of this study are available from the corresponding author upon request.

\section{Conflicts of Interest}

The authors declare that they have no conflicts of interest.

\section{Acknowledgments}

This research was funded by the National Natural Science Foundation of China (no. 51604094 and no. 51904177), and the Research Fund of State and Local Joint Engineering Laboratory for Gas Drainage \& Ground Control of Deep Mines (Henan Polytechnic University)(no. SJF201807)

\section{References}


Tang JH, Chen XD, Dai F (2020) Experimental study on the crack propagation and acoustic emission characteristics of notched rock beams under post-peak cyclic loading. Eng Fract Mech 226: doi:10.1016/j.engfracmech.2020.106890

Yang YZ, Zhang ZN (2020) Dynamic fracturing process of fissured rock under abrupt unloading condition: A numerical study. Eng Fract Mech 231: doi:10.1016/j.engfracmech.2020.107025

Yang SQ, Huang YH, Liu XR (2014) Analysis of tensile strength and crack propagation particle flow in intermittent double fractured rock. Journal China Univ Min Technol 43(2):220-226

Huang D, Yan DuF (2013) Mechanical response and energy dissipation mechanism of single-slot static-dynamic compression-soil single-fracture rock mass simulation . Chin J Rock Mech Eng 32(9): 1926-1936

Tian WL, Yang SQ, Huang YH (2017) Particle flow simulation of crack evolution characteristics of coplanar double-fractured brittle sandstone under different confining pressures . J Min Saf Eng 34(6): 1207-1215

$\underline{\text { Pan WD }}$, Wang X, Liu QM, Yuan YK, Zuo BD (2019) $\underline{\text { Non-parallel double-crack propagation in rock-like materials under uniaxial }}$ compression . Int J Coal Sci Technol 6(3):372-387

Zhou Y, Wu SC, Xu XL (2013) Particle flow simulation of macroscopic and micromechanical behavior of non-coplanar double-fracture red sandstone. Chin J of Rock Mech Eng 32(5): 951-959

Wang YL, Tang JX, Dai ZY, Yi T (2018) Experimental study on mechanical properties and failure modes of low-strength rock samples containing different fissures under uniaxial compression. Eng Fract Mech 197: 1-20

Kucewicz M, Baranowski P, Małachowski J (2020) Determination and validation of Karagozian-Case Concrete constitutive model parameters for numerical modeling of dolomite rock. Int J Rock Mech Min Sci 129:

Li TT, Pei XJ, Wang DP, Huang RQ, Tang H (2019) Nonlinear behavior and damage model for fractured rock under cyclic loading based on energy dissipation principle. Eng Fract Mech 2061: 330-341

Silva VR, Ranjith PG (2020) A study of rock joint influence on rock fracturing using a static fracture stimulation method. $\underline{\text { J Mech Phys }}$ Solids 137: doi: 10.1016/j.jmps.2019.103817

Baranowski P, Kucewicz M, Gieleta R, Stankiewicz M, Małachowski J (2020) Fracture and fragmentation of dolomite rock using the JH-2 constitutive model: Parameter determination, experiments and simulations. Int J Impact Eng 140: doi: 10.1016/j.ijimpeng.2020.103543

Mahnaz L, Alireza B, Hamid HH, Mohsen D (2018) Numerical determination of deformability and strength of 3D fractured rock mass. Int J Rock Mech Min Sci $\quad$ 110: 246-256

Ju Y, Sun HF, Xing MX, Wang XF, Zheng JT (2018) Numerical analysis of the failure process of soil-rock mixtures through computed tomography and PFC3D models. Int J Coal Sci Technol 5(2): 126-141

Mu K, Yu Wi, Li H et al (2015) Particle flow simulation of acoustic emission and energy dissipation of sandstone under water-force coupling. Rock Soil Mech 36(5): 1496-1504

Liu WR, Liu J, Zhu C. (2019) Multi-scale effect of acoustic emission characteristics of 3D rock damage. Arabian J Geosci 12(22): $668-678$

Mardalizad A, Saksala T, Manes A, Giglio M (2020) Numerical modeling of the tool-rock penetration process using FEM coupled with

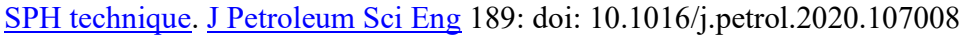

Qiu JD, Luo L, Li XB, Li DY, Luo Y (2020) Numerical investigation on the tensile fracturing behavior of rock-shotcrete interface $\underline{\text { based on discrete element method. Int J Min Sci Technol doi:10.1016/j.ijmst.2020.03.007 }}$

Park CH, Bobet A (2009) Crack coalescence in specimens with open and closed flaws: a comparison. Int J Rock Mech Min Sci 46(5): 819-829

Lee H, Jeon S (2011) An experimental and numerical study of fracture coalescence in pre-cracked specimens under uniaxial compression . Int J Solids Structures 48(6):979-999

Ha YD, Lee J, Hong JW (2015) Fracturing patterns of rock-like materials in compression captured with peridynamics . Eng Fract Mech 144: 176-193

Cheng XY (2019) Damage and failure characteristics of rock similar materials with pre-existing cracks (Open Access) . Int J Coal 
Sci Technol 6(4): 505-517

Fu MX, Liu SW, Jia HS, He DY (2020) Experimental study of an orientation and resin lifting device for Improving the performance of resin anchored roof Bolts. Rock Mech Rock Eng 53(1):211-231

Fu MX, Liu SW, Su FQ (2018) An experimental study of the vibration of a drill rod during roof bolt installation. Int J Rock Mech Min Sci 104: 20-26

Liu SW, Fu MX, Jia HS, Li WB (2018) Shear Characteristics of Cuneiform Reaming Anchorage Bolts in Coal Mine Roadways. Rock Mech Rock Eng 52(6): 1931-1943

Ghadirian HR, Akbardoost J, Zhaleh AR (2019) Fracture analysis of rock specimens weakened by rounded-V and U-shaped notches under pure mode I loading. Int J Rock Mech Min Sci 123: doi: 10.1016/j.ijrmms.2019.104103

Sangsefidi M, Akbardoost J, Mesbah M (2020) Experimental and theoretical fracture assessment of rock-type U-notched specimens under mixed mode I/II loading. Eng Fract Mech 230: doi: 10.1016/j.engfracmech.2020.106990

Xie HP, Peng RD, Ju Y (2005) On energy analysis of rock failure. Chin J Rock Mech Eng 24(15): 2604-2608

Deng HF, Hu Y, Li JL (2016) Evolution of sandstone energy dissipation during cyclic loading and unloading. J Rock Mech Eng 35 (Suppl.1): 2869-2875

Peng RD, Ju Y, Gao F (2014) Energy analysis on damage of coal under cyclical triaxial loading and unloading conditions. J China Coal Soc 39(2) : 245-252

Zhao YX, Gong S, Huang YQ (2015) Experimental study on energy dissipation characteristics of dynamic tensile splitting of coal samples under impact loading. J China Coal Soc 40(10): 2320-2326 
Figures

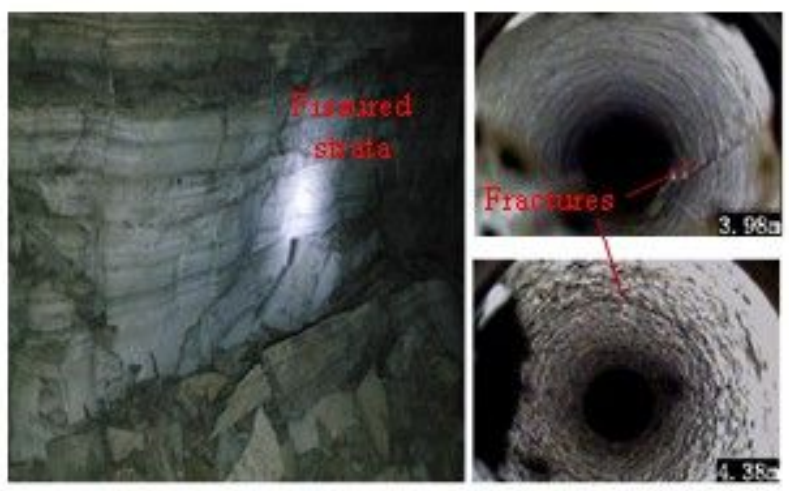

\section{Figure 1}

Fissured pillars and roadway roof fissures
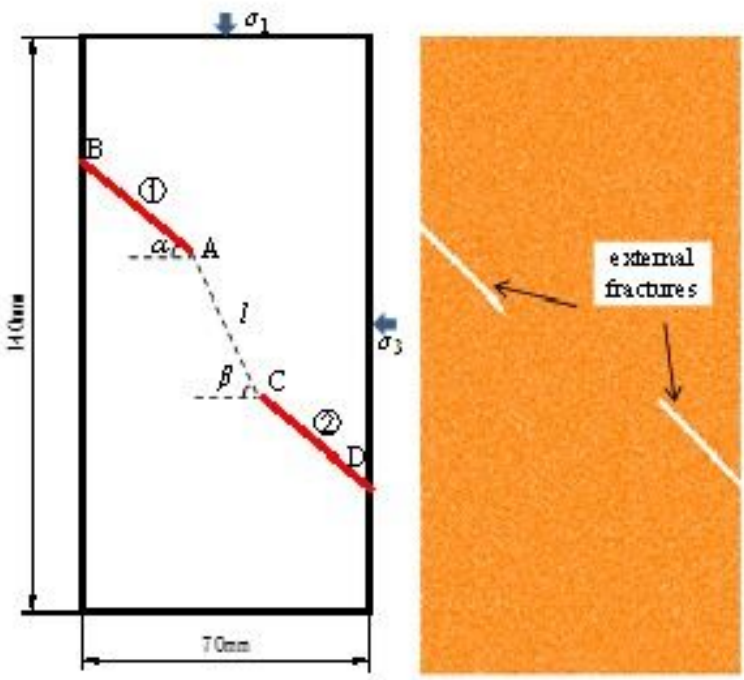

Figure 2

Numerical sandstone model containing external double-fissures 


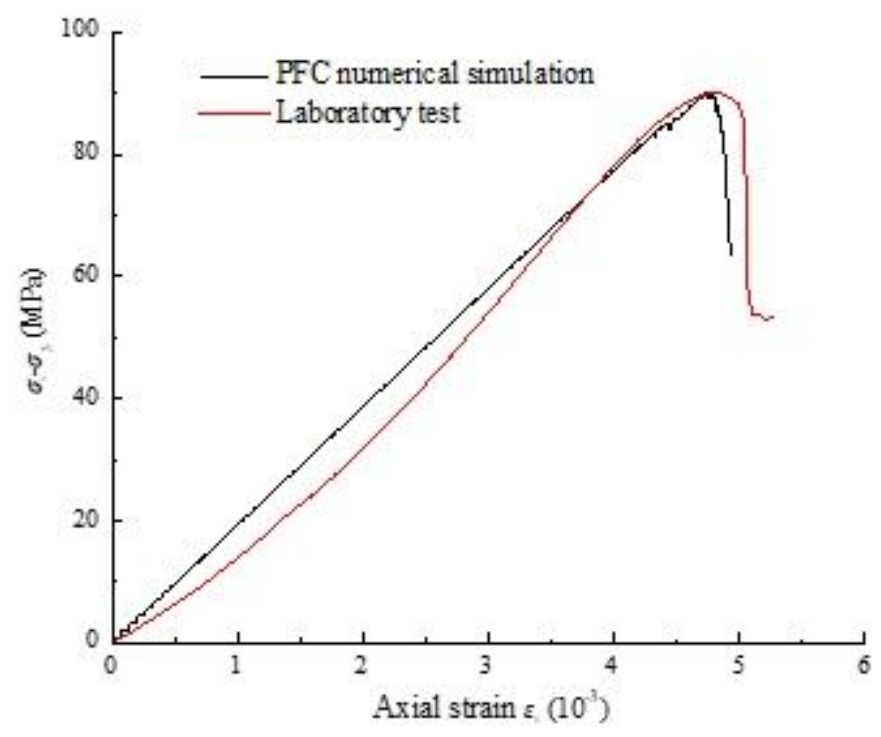

Figure 3

Stress curve for the laboratory test and PFC simulation under triaxial compression

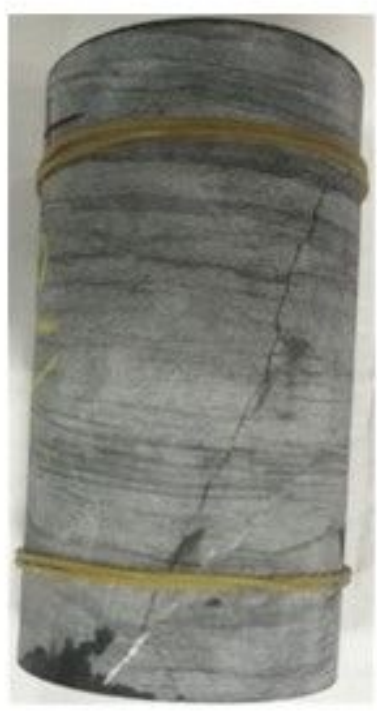

(a) Laboratory test

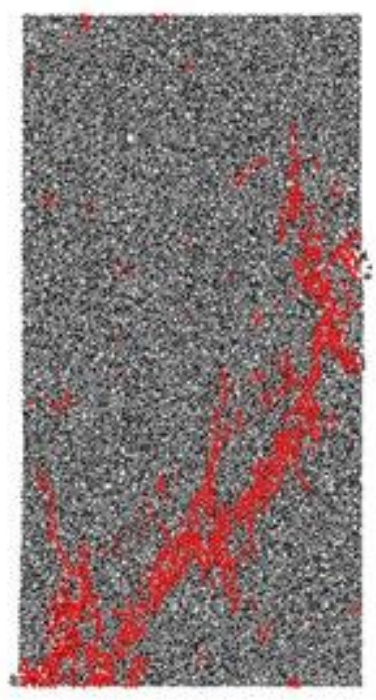

(b) PFC simulation

\section{Figure 4}

Macro-fracturing patterns recovered for the laboratory test and PFC simulation under triaxial compression 


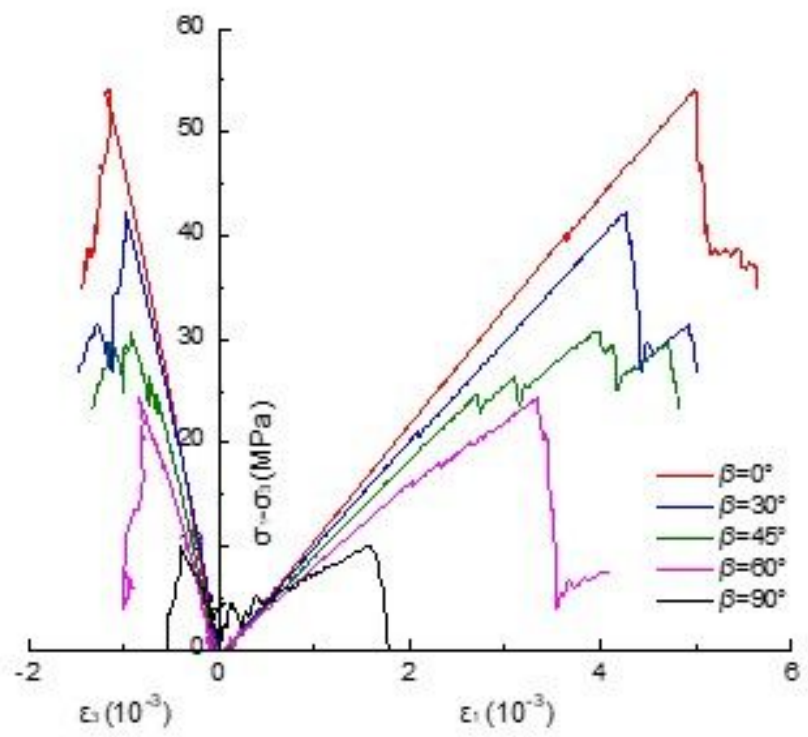

(a) $\sigma_{3}=10 \mathrm{MPa}$

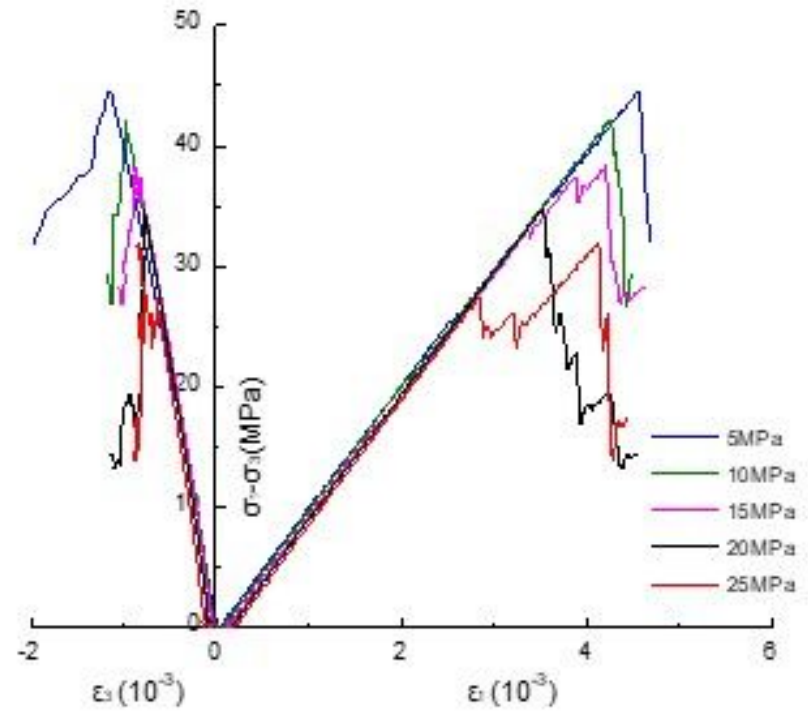

(b) $\beta=30^{\circ}$

Figure 5

Stress-strain curve for externally double-fissured sandstone 


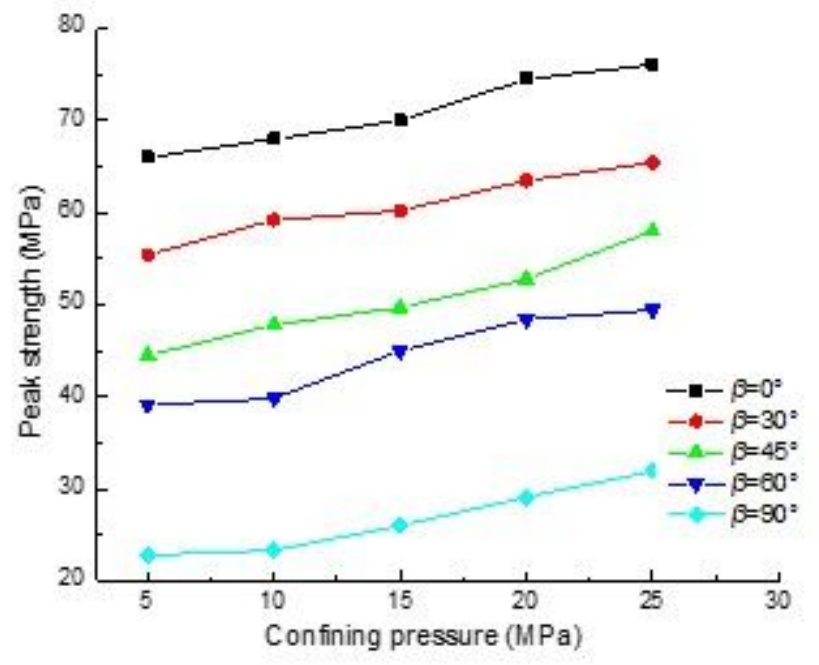

Figure 6

Peak strength values for externally fissured sandstone 


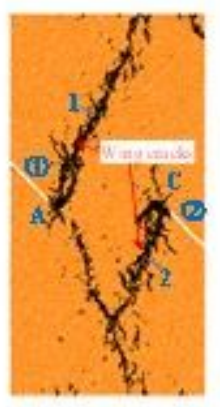

$\hat{g}=0^{2}$

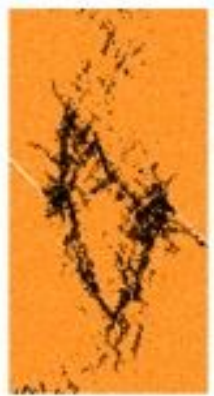

$\hat{g}=10^{2}$

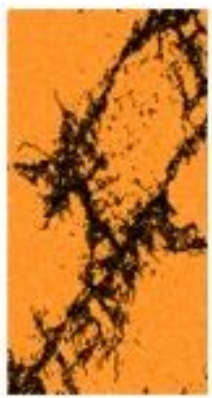

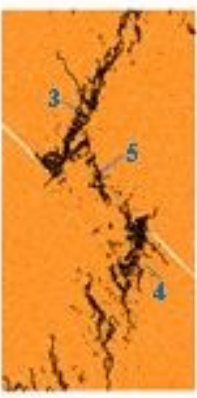

$\hat{\theta}=30^{2}$

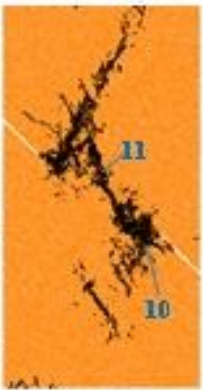

$\hat{p}=3 r^{2}$

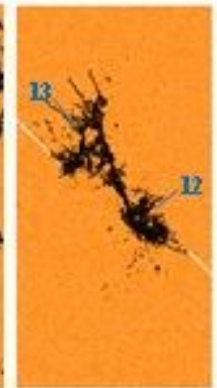

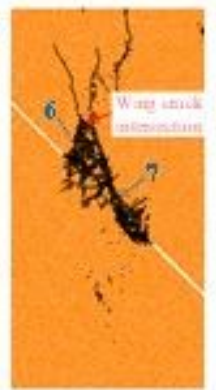

$\hat{b}=45^{2}$ (a) $\Rightarrow=5 \mathrm{MPa}$

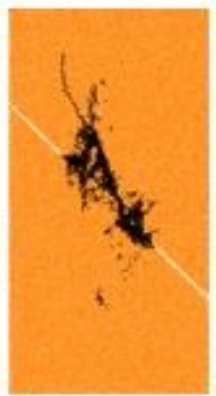

$\hat{\beta}=45^{2}$

(b) $\sigma_{1}=15 \mathrm{MP} 2$

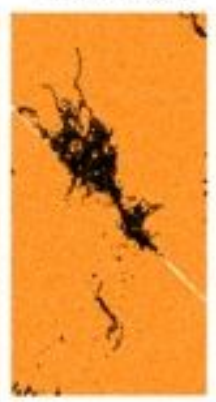

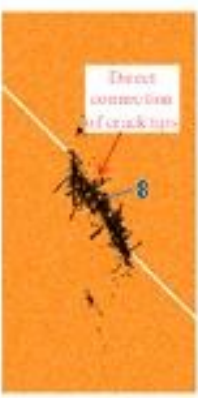

$\hat{g}=60^{2}$

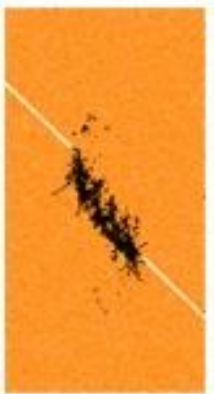

$\hat{j}=60^{2}$

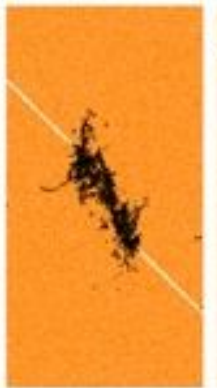

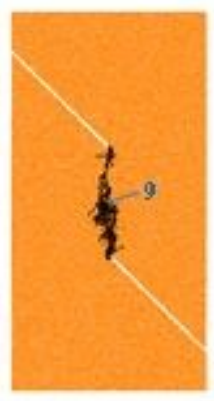

$\hat{j}=90^{\circ}$

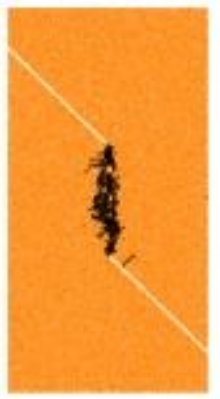

$\hat{f}=90^{2}$

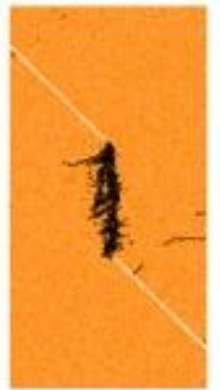

Figure 7

Final fracturing patterns seen in externally fissured sandstone samples

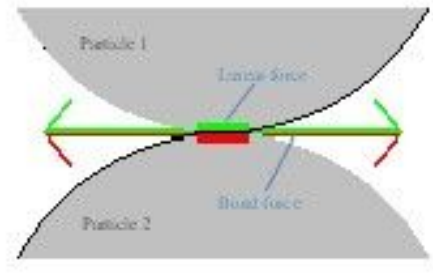

(a) Particle cousact

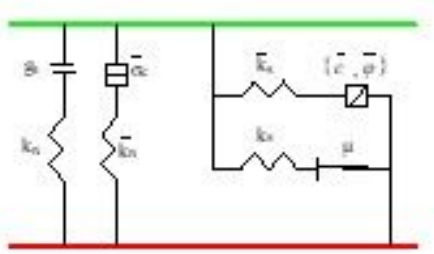

(b) Bend foece interface

Figure 8

Parallel bonded contact mechanics model 


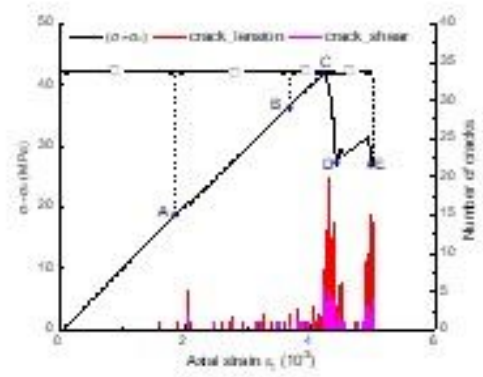

Figure 9

The evolution of deviator stress and micro-cracks with axial strain

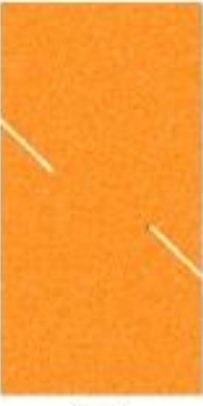

Point A

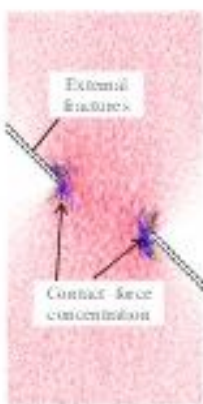

$P_{\max }=125 \mathrm{ke}$

Point A

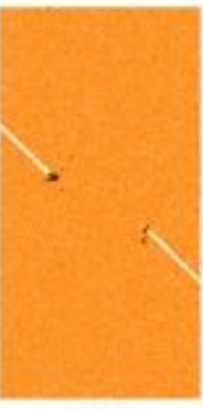

Point B
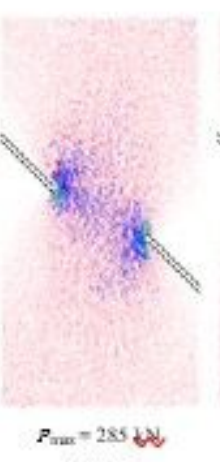

Point B

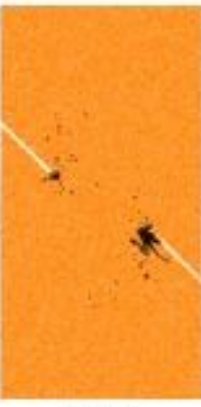

Point $C$ (a) Crack evolution
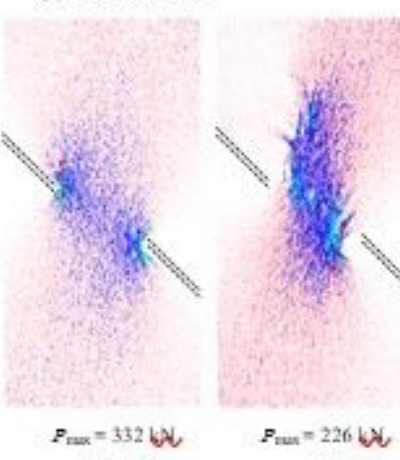

$$
\text { Point } C
$$

(b) Particle contact force evolution

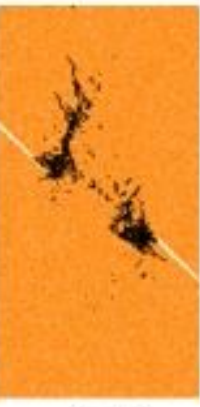

Poiat D

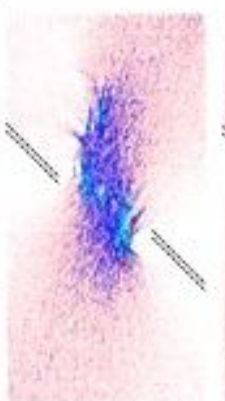

$P_{\operatorname{man}}=2266 \alpha$

Point 19

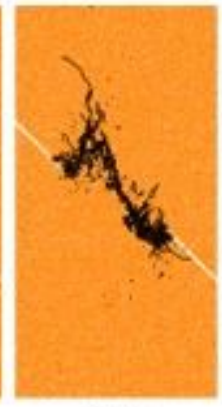

Point E.

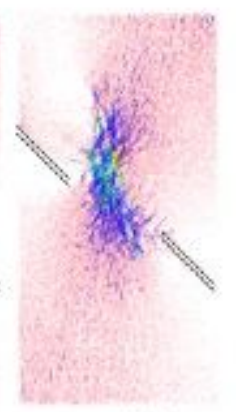

$=P_{\operatorname{man}}=201 \mathrm{kN}$ Point $\mathrm{E}$

\section{Figure 10}

The evolution of micro-cracks and particle contact force distribution 


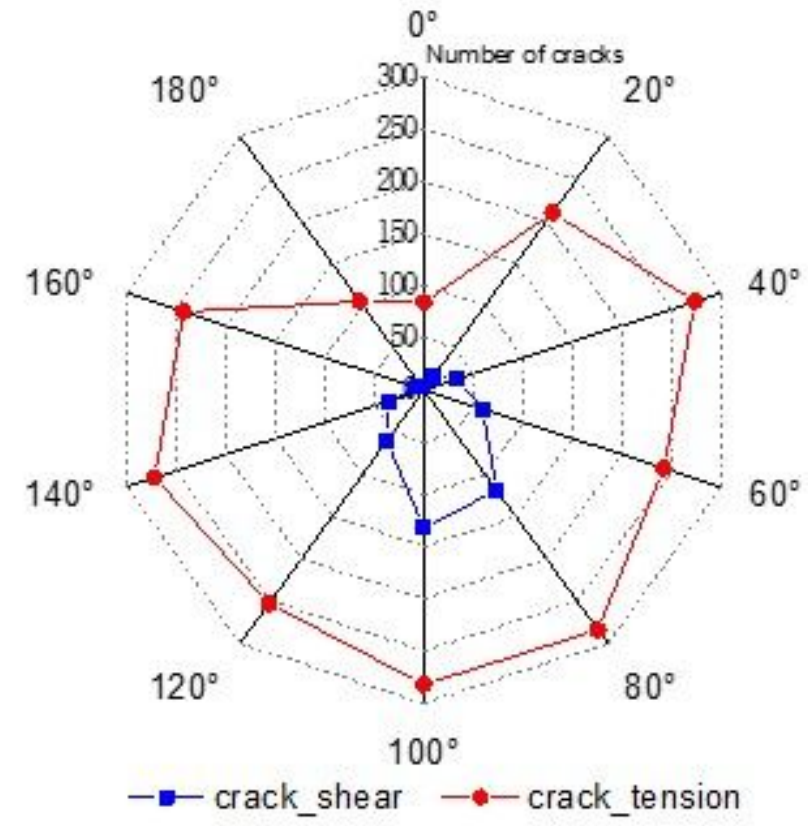

Figure 11

Micro-crack distribution

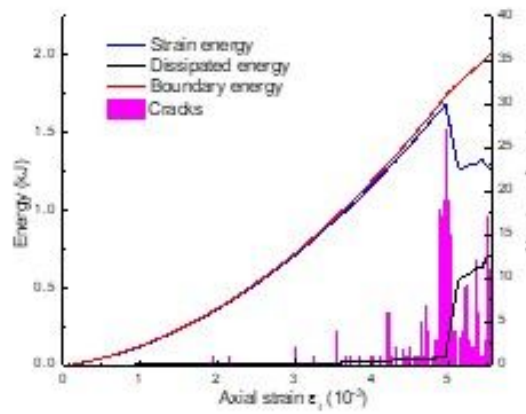

$\beta=0^{\circ}$

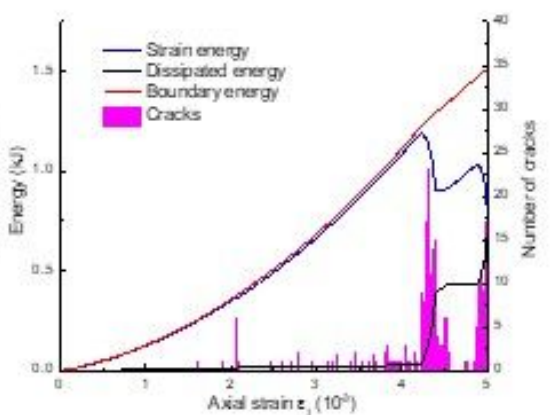

$\beta=30^{\circ}$

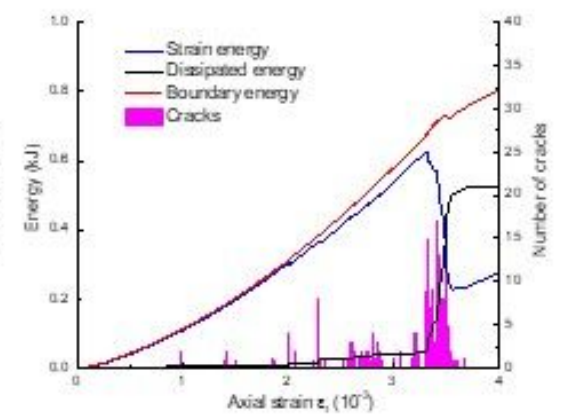

$\beta=60^{\circ}$

(a) $\sigma_{3}=10 \mathrm{MPa}$

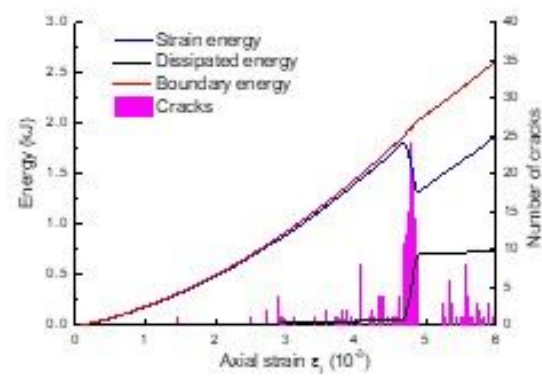

$\beta=0^{\circ}$

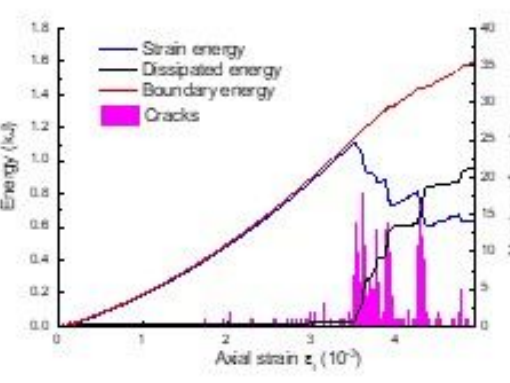

$\beta=30^{\circ}$

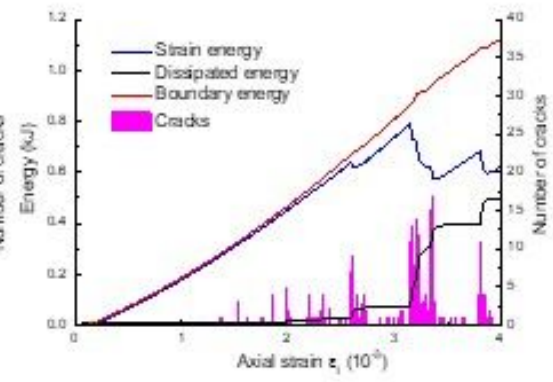

$\beta=60^{\circ}$

(b) $\sigma_{3}=20 \mathrm{MPa}$ 
Figure 12

Energy evolution curve for an externally fissured sandstone

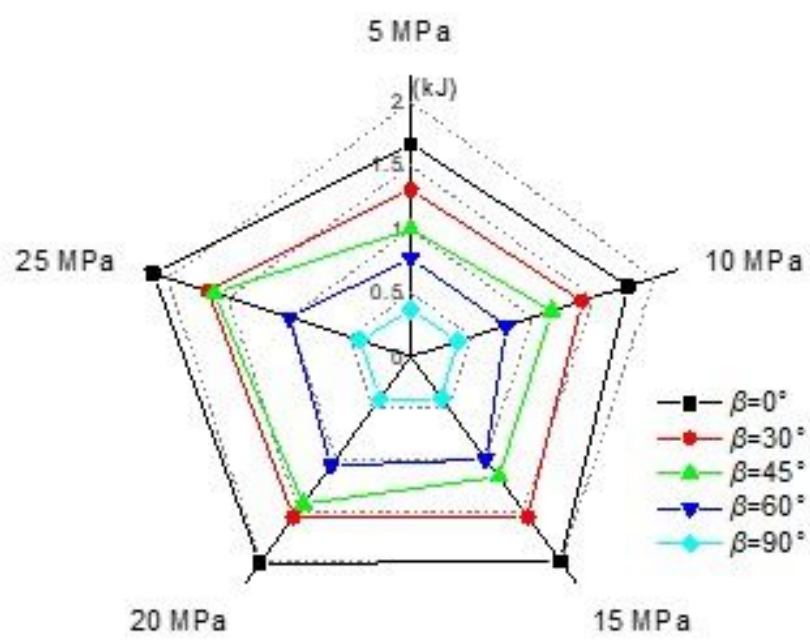

Figure 13

Energy and crack evolution in an externally fissured sandstone

(a) Strain energy

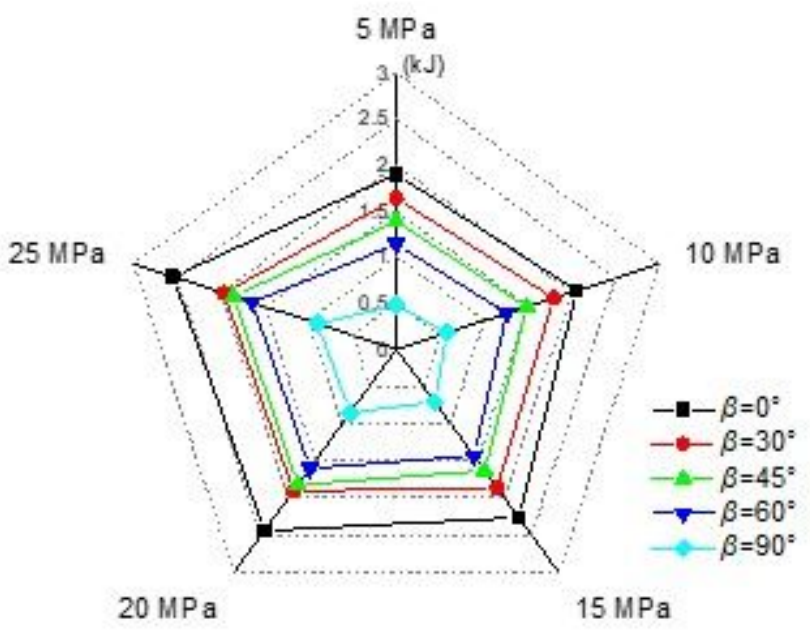

(b) Boundary energy 
Figure 14

The relationship between peak boundary energy and confining pressure

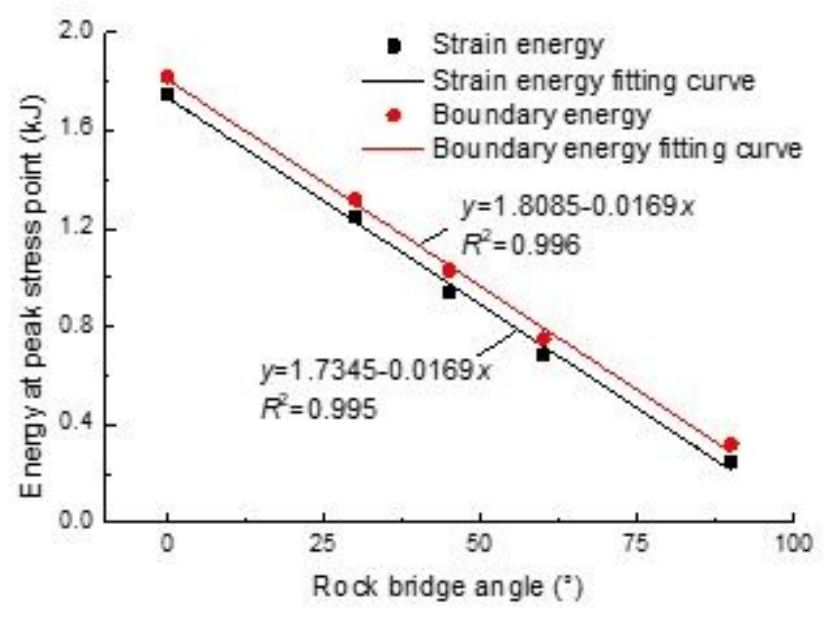

\section{Figure 15}

The relationship between peak energy and rock bridge angle in an externally fissured sandstone when $\sigma 3$ $=10 \mathrm{MPa}$ 